\begin{abstract}
INTERNATIONAL
\title{
Single-piece all-solid-state Co(II) ion-selective electrode for cobalt monitoring in real samples**
}

\author{
Cecylia Wardak*(1) and Matgorzata Grabarczyk \\ Department of Analytical Chemistry and Instrumental Analysis, Maria Curie-Skłodowska University, \\ Maria Curie-Skłodowska Sq. 3, 20-031 Lublin, Poland \\ Received August 30, 2018; accepted April 11, 2019
}

\begin{abstract}
A novel single-piece all-solid-state ion-selective electrode for $\mathrm{Co}^{2+}$ determination has been prepared. The PVC membrane was modified by the addition of ionic liquid. The effect of various ionic liquids was studied in detail and improved performance was observed. The best performance exhibited by the electrode was achieved with a membrane containing 1-ethyl3-methyl imidazolium chloride, having a slope of $31.8 \mathrm{mV} /$ decade in a wide concentration range of $1 \times 10^{-7}-1 \times \times 10^{-1} \mathrm{~mol} \mathrm{~L}^{-1}$. The limit of detection was $5.6 \times 10^{-8} \mathrm{~mol} \mathrm{~L}^{-1}$. The response time of the proposed sensor was less than $10 \mathrm{~s}$ and the lifetime was at least three months. The proposed sensor showed good selectivity towards the $\mathrm{Co}^{2+}$ ion in comparison with some alkali, alkaline earth, transition and heavy metal ions. It was successfully applied for the direct determination of cobalt ions in real sample solution.

Keywords: cobalt(II) ion-selective electrode, ionic liquids, solid contact, potentiometry
\end{abstract}

\section{INTRODUCTION}

Cobalt is an environmentally ubiquitous element. It is a component of more than 70 naturally occurring minerals and it has been found in every part of the environment including air, surface water, groundwater, soil, and sediment (Kim et al., 2006). The presence of cobalt in the environment is also connected with the wide application of its compounds in many industrial processes, fertilizers, paint products, batteries, feeds and disinfectants. Cobalt is an element, which is essential for life as it is a component of vitamin $\mathrm{B}_{12}$ and enzymes such as carbonic anhydrases and alkaline phosphatases (Pais and Jones, 1997; Arinola et al., 2008). A cobalt deficiency may cause the inhibition of the synthesis of thymidine, anaemia, the degeneration of nerve cells and the impairment of metabolic processes (Barceloux, 1999). On the other hand, large doses of this

\footnotetext{
*Corresponding author e-mail: cecylia.wardak@poczta.umcs.lublin.pl
}

metal may lead to erythraemia, cancers, and hypertrophy of the thyroid gland, as well as damage to the veins, liver and heart (Fisher and Rystedt, 1985; Moulin et al., 1993). Cobalt is one of the trace elements which are necessary for the methanogenesis performed by microorganisms (Kida et al., 2001). It is known that a deficiency of trace element such as cobalt may result in process instability and decreased biogas production. Hence the addition of cobalt, nickel and other trace elements to bioreactors is used to create optimal conditions for the microorganisms present in the digester and improve the capacity of biogas plants. On the other hand supplementation with trace metals could lead to an increase in the amounts of these metals released into the environment. Concentrations of cobalt in surface water and groundwater are usually low, about 1-10 $\mu \mathrm{g} \mathrm{L}^{-1}$ in populated areas. Nevertheless, the cobalt content in such locations may be much higher in mining and agricultural areas, even up to hundreds of $\mathrm{mg} \mathrm{L}^{-1}$ (Kim et al., 2006). In water samples cobalt is generally present in the form of inorganic $\mathrm{Co}^{2+}$, which can be detected easily and determined by cobalt ion-selective electrodes.

Potentiometry, with an ion-selective electrode is a quick, simple and economic analytical method facilitating the direct determination of many elements in their ionic forms in various samples including environmental, industrial and clinical ones (Pięk et al., 2015; Wardak and Grabarczyk, 2016; Lenik and Lyszczek, 2016; Maj-Zurawska and Lewenstam, 2011). In order to obtain accurate results, the use of a sensor with an appropriate detection limit is required, it is also beneficial if it displays selectivity towards interfering ions, which may potentially occur in the tested

(C) 2020 Institute of Agrophysics, Polish Academy of Sciences 
sample. From a practical point of view, it is also important for the electrode to feature a short response time as well as stability and potential reproducibility (Lindner and Umezawa, 2008). Solid-contact ion-selective electrodes, with a polymer membrane without an internal electrolyte, have aroused increasing interest in recent years. In comparison with classic electrodes with an internal filling solution, this type of sensor has a significantly lower cost, and is simpler to use and transport, as well as being more mechanically resistant. Moreover, they can work in any position, in special pressure conditions and within a wide range of temperatures. Unfortunately, the direct connection between the electronic conductors and ionically conducting membranes may lead to a large potential drift due to the high resistance of the charge transfer (Hauser et al., 1995). The most popular solution to the elimination of these problems was the application of an intermediate layer of various conducting polymers with mixed ionic and electronic conductivity (Cadogan et al., 1992; Paczosa-Bator et al., 2006; Michalska et al., 2009; Guziński et al., 2013). However, conducting polymer-based electrodes may exhibit disadvantages such as $\mathrm{CO}_{2}, \mathrm{pH}$ or light sensitivity (Bobacka et al., 2008; Lindfors, 2009), as well as a water layer forming at the interface (Fibbioli et al.2000; Lindfors et al., 2009).

In recent years it was found that ionic liquids (ILs) may be used to replace commonly used lipophilic ionic additives (phenyl borates) in the membrane phase (Wardak, 2009; Wardak, 2012a; Wardak, 2015). They lower the resistance of the membrane and reduce anion interference, thereby improving certain analytical parameters of the electrode, such as the detection limit, measuring range, working $\mathrm{pH}$ range and selectivity. Therefore, we have decided to prepare a single-piece solid-contact cobalt ion-selective electrode with a membrane modified by IL. As a cobalt ionophore, 2-amino-5(Hydroxy-1-naphthylazo)-1,3,4 -thiadiazole was used. This compound forms stable complexes with cobalt, which are soluble in membrane solvents. For membrane modification, various alkylmethylimidazolium ionic liquids with chloride anions were used. The proposed electrode is based on the concept of a second kind of $\mathrm{Ag} /$ $\mathrm{AgCl}$ electrode. Thus, the addition of an ionic liquid in chloride form to the membrane covering this internal $\mathrm{Ag}$ / $\mathrm{AgCl}$ electrode will eliminate the blocked membrane/internal electrode interface.

Electrodes containing a membrane with a traditional composition without ionic liquid were prepared and studied in order to serve as a comparison with the proposed electrode.

\section{MATERIALS AND METHODS}

The following reagents were used: Ionic liquids:

1-ethyl-3-methylimidazolium chloride (EMImCl), 1-butyl-3-methylimidazolium chloride (BMImCl), 1-hexyl-3-methylimidazolium chloride ( $\mathrm{HMImCl})$, 1-methyl-3-octylimidazolium chloride (OMImCl), 1-decyl-3-methylimidazolium chloride (DMImCl), were obtained from Sigma-Aldrich. Poly(vinyl chloride) low molecular weight (PVC) was purchased from Aldrich. As PVC plasticizers: 2-Nitrophenyl octyl ether (NPOE) (Fluka), tributyl phosphate (TBP) (Merck) and tris(2ethylhexyl) phosphate (TEHP)(K\&K laboratories ICN) were used. The ionophore 2-amino-5(Hydroxy-1-naphthylazo)-1,3,4 -thiadiazole (I) was synthesized at the Department of Medical Chemistry, Medical University of Lublin. As a traditional lipophilic additive, potassium tetrakis ( $p$-chlorophenyl) borate $(\mathrm{KTpClB})$ (Fluka) was used. Other reagents were purchased from Fluka. All aqueous solutions were prepared with compounds of the highest purity available (pure pro analysis) using freshly deionized water.

Ion-selective electrodes were constructed using an $\mathrm{Ag} / \mathrm{AgCl}$ electrode as the internal electrode which was obtained in the electrolysis process. The electrode membrane covering the internal $\mathrm{Ag} / \mathrm{AgCl}$ electrode was prepared by the gelation of the mixture of membrane components placed in the Teflon holder. The method of membrane preparation was described in detail in our earlier papers (Wardak, 2009; Wardak and Lenik, 2013). After preparation, the electrodes were soaked for at least $12 \mathrm{~h}$, in a $1 \times 10^{-3} \mathrm{~mol} \mathrm{~L}^{-1} \mathrm{Co}\left(\mathrm{NO}_{3}\right)_{2}$ solution to saturate the $\mathrm{PVC}$ membrane in the primary ions. In order to optimize the electrode detection limit before measurements were carried out, the electrodes were conditioned for at least $24 \mathrm{~h}$, in an appropriate conditioning solution. The concentrations of the conditioning solutions were as follows: a) $1 \times 10^{-3} \mathrm{~mol} \mathrm{~L}^{-1}$, b) $1 \times 10^{-5} \mathrm{~mol} \mathrm{~L}^{-1}$, c) $1 \times 10^{-7} \mathrm{~mol} \mathrm{~L}^{-1}$ and d) $1 \times 10^{-9} \mathrm{~mol} \mathrm{~L}^{-1}$.

The scheme of sensor construction is shown in Fig. 1. The membrane composition is listed in Table 1.

The measurement of the electromotive force (EMF) of the system: the cobalt ion-selective electrode - reference electrode Orion 90-02 was carried out at room temperature in a solution stirred with a magnetic stirrer by means of a potentiometric system consisting of a 16-channel data acquisition system (Lawson Labs. Inc., USA) and IBM PC computer. Sequential dilutions of stock solutions were performed using the 700 Dosino and 711 Liquino pump systems (Metrohm, Switzerland).

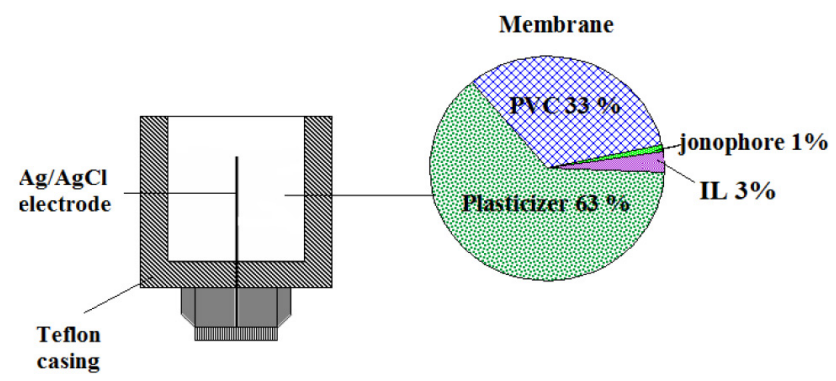

Fig. 1. Scheme of electrode construction and membrane composition. 
Table 1. Composition of electrode membranes and sensors performance

\begin{tabular}{|c|c|c|c|c|c|}
\hline \multirow{2}{*}{$\begin{array}{l}\text { No. } \\
\text { electrode }\end{array}$} & \multicolumn{2}{|c|}{ Membrane composition (\% wt.) } & \multirow{2}{*}{$\begin{array}{c}\text { Limit } \\
\text { detection } \\
\left.(\mu \mathrm{mol} \mathrm{L})^{-1}\right)\end{array}$} & \multirow{2}{*}{$\begin{array}{c}\text { Slope } \\
(\mathrm{mV} / \\
\text { decade) }\end{array}$} & \multirow{2}{*}{$\begin{array}{l}\text { Measuring range } \\
\quad\left(\mathrm{mol} \mathrm{L}^{-1}\right)\end{array}$} \\
\hline & Plasticizer & Ionic liquid & & & \\
\hline ISE-1 & TBP, 63 & EMImCl, 3 & $1.31 \pm 0.12$ & $30.81 \pm 0.26$ & $1.0 \times 10^{-5}-1.0 \times 10^{-1}$ \\
\hline ISE-2 & TBP, 63 & $\mathrm{BMImCl}, 3$ & $3.30 \pm 0.17$ & $28.72 \pm 0.31$ & $1.0 \times 10^{-5}-1.0 \times 10^{-1}$ \\
\hline ISE-3 & TBP,63 & HMImCl, 3 & $3.52 \pm 0.22$ & $28.23 \pm 0.16$ & $1.0 \times 10^{-5}-1.0 \times 10^{-1}$ \\
\hline ISE-4 & TBP, 63 & $\mathrm{OMImCl}, 3$ & $6.18 \pm 0.27$ & $23.91 \pm 0.35$ & $1.0 \times 10^{-5}-1.0 \times 10^{-1}$ \\
\hline ISE-5 & TBP, 63 & DMImCl, 3 & $7.82 \pm 1.12$ & $28.88 \pm 0.32$ & $5.0 \times 10^{-5}-1.0 \times 10^{-1}$ \\
\hline ISE-6 & TBP, 66.5 & KTpCIPB, 0.5 & $13.2 \pm 2.7$ & $29.11 \pm 0.40$ & $5.0 \times 10^{-5}-1.0 \times 10^{-1}$ \\
\hline ISE-7 & NPOE, 63 & EMImCl, 3 & $6.61 \pm 0.14$ & $29.35 \pm 0.19$ & $1.0 \times 10^{-5}-1.0 \times 10^{-1}$ \\
\hline ISE-8 & NPOE, 63 & $\mathrm{BMImCl}, 3$ & $5.65 \pm 0.13$ & $28.71 \pm 0.23$ & $1.0 \times 10^{-5}-5.0 \times 10^{-1}$ \\
\hline ISE-9 & NPOE, 63 & HMImCl, 3 & $7.13 \pm 0.23$ & $28.39 \pm 0.31$ & $1.0 \times 10^{-5}-1.0 \times 10^{-1}$ \\
\hline ISE-10 & NPOE, 63 & OMImCl, 3 & $18.4 \pm 1.1$ & $26.16 \pm 0.22$ & $5.0 \times 10^{-5}-1.0 \times 10^{-1}$ \\
\hline ISE-11 & NPOE, 63 & DMImCl, 3 & $35.2 \pm 2.7$ & $28.82 \pm 0.16$ & $1.0 \times 10^{-4}-1.0 \times 10^{-1}$ \\
\hline ISE-12 & NPOE, 65.5 & KTpClPB, 0.5 & $46.5 \pm 4.4$ & $30.55 \pm 0.28$ & $1.0 \times 10^{-4}-1.0 \times 10^{-1}$ \\
\hline ISE-13 & $\begin{array}{l}\text { TBP, } 31.5 \\
\text { TEHP, } 31.5\end{array}$ & $\mathrm{EMImCl}, 3$ & $0.29 \pm 0.10$ & $31.20 \pm 0.18$ & $1.0 \times 10^{-6}-1.0 \times 10^{-1}$ \\
\hline ISE-14 & $\begin{array}{l}\text { TBP, } 31.5 \\
\text { TEHP, } 31.5\end{array}$ & $\mathrm{BMImCl}, 3$ & $0.95 \pm 0.16$ & $29.92 \pm 0.22$ & $5.0 \times 10^{-6}-1.0 \times 10^{-1}$ \\
\hline ISE-15 & $\begin{array}{l}\text { TBP, } 31.5 \\
\text { TEHP, } 31.5\end{array}$ & HMImCl, 3 & $1.96 \pm 0.21$ & $28.36 \pm 0.16$ & $5.0 \times 10^{-6}-1.0 \times 10^{-1}$ \\
\hline ISE-16 & $\begin{array}{l}\text { TBP, } 31.5 \\
\text { TEHP, } 31.5\end{array}$ & OMImCl, 3 & $2.92 \pm 0.34$ & $30.22 \pm 0.13$ & $1.0 \times 10^{-5}-1.0 \times 10^{-1}$ \\
\hline ISE-17 & $\begin{array}{l}\text { TBP, } 31.5 \\
\text { TEHP, } 31.5\end{array}$ & $\mathrm{DMImCl}, 3$ & $3.93 \pm 0.21$ & $29.33 \pm 0.23$ & $1.0 \times 10^{-5}-1.0 \times 10^{-1}$ \\
\hline ISE-18 & $\begin{array}{l}\text { TBP, } 32.75 \\
\text { TEHP, } 32.75\end{array}$ & KTpClPB, 0.5 & $3.2 \pm 0.56$ & $28.81 \pm 0.51$ & $1.0 \times 10^{-5}-1.0 \times 10^{-1}$ \\
\hline
\end{tabular}

Content of ionophore and PVC was the same for all electrodes $1 \% \mathrm{wt}$. and $33 \% \mathrm{wt}$., respectively.

The potentiometric responses of the studied electrodes were determined in cobalt nitrate solutions with a concentration of $1 \times 10^{-1}-1 \times 10^{-8} \mathrm{~mol} \mathrm{~L}^{-1}$. The calibration curves were determined four times in an alternating fashion, from low to high and high to low concentrations. The sensor performance of individual electrodes such as the limit of detection, the working concentration range, and the slope of the linear section of the response curve, were determined from the results of these measurements and are summarized in Table 1. The detection limit given in Table 1 was taken as the bulk activity when the measured potential begins to deviate on both sides, by $\left(\mathrm{RT} / \mathrm{z}_{\mathrm{i}} \mathrm{F}\right) \ln 2$ from the linear Nernstian response (Sokalski et al., 1999).

The selectivity of the studied sensors wereas evaluated by determining the selectivity coefficient values using the separate solution method, which is known as Bakker's method (Bakker et al., 2000).

The response times of the examined electrodes was determined from the dynamic response obtained by injecting concentrated standard solutions into a stirred sample solution and simultaneously recording EMF changes with time. The response time was determined as the elapsed time from the moment when the studied cobalt-selective electrode and reference electrode are brought into contact with a sample solution with a changed activity of the $\mathrm{Co}^{2+}$ ions to the time when the $\Delta \mathrm{E} / \Delta \mathrm{t}$ becomes equal to $0.5 \mathrm{mV} \mathrm{min}^{-1}$ (Buck and Lindner, 1994).

In order to evaluate the reversibility of the potential, the studied electrodes were immersed repetitively in $\mathrm{Co}\left(\mathrm{NO}_{3}\right)_{2}$ solutions at two different concentrations $\left(1 \times 10^{-5}\right.$ and $1 \times 10^{-6}$ $\left.\mathrm{mol} \mathrm{L} \mathrm{L}^{-1}\right)$ and electrode response was measured.

The long-term stability and reproducibility of the electrode potentials were studied over a 90 -day period. The measurements were conducted using three identical electrodes in $0.1 \mathrm{~mol} \mathrm{~L}^{-1} \mathrm{Co}\left(\mathrm{NO}_{3}\right)_{2}$ solutions. The potentials were measured daily during the first three days and then every five days. The electrodes were stored in air without sunlight between measurements. The potential readings of particular electrodes obtained after 60 min were used to calculate the mean potential values and standard deviations of each measurement.

Electrochemical impedance spectroscopy (EIS) measurements were performed in $0.01 \mathrm{~mol} \mathrm{~L}^{-1} \mathrm{Co}\left(\mathrm{NO}_{3}\right)_{2}$ by using an AUTOLAB electrochemical analyser controlled by 
GPES software, ver. 4.9 (Eco Chemie Utrecht Netherlands) with a conventional three-electrode system, where the studied electrode was used as the working electrode, the reference electrode was $\mathrm{Ag} / \mathrm{AgCl}\left(3 \mathrm{~mol} \mathrm{~L}^{-1} \mathrm{KCl}\right)$, and the auxiliary electrode was a platinum wire. The impedance spectra were recorded at open circuit potential with an amplitude of $0.1 \mathrm{~V}$ and in the frequency range $100 \mathrm{~Hz}-100 \mathrm{kHz}$.

All water samples were collected in the village of Siedliszczki in eastern Poland in April 2018. Three kinds of water samples were analysed: water taken from the river Gielczew was slightly turbid and had a conductivity of $0.55 \mathrm{mS} \mathrm{cm}^{-1}$; water from a small unnamed lake was slightly turbid and had a conductivity of $0.68 \mathrm{mS} \mathrm{cm}^{-1}$; ground water taken from a well was clear and had a conductivity of $0.30 \mathrm{mS} \mathrm{cm}^{-1}$. Directly after sampling, the water samples were acidified with $0.1 \mathrm{~mol} \mathrm{~L}^{-1} \mathrm{HNO}_{3}$ to reach a stable $\mathrm{pH}$ of 5.0. Portions of $100 \mathrm{~mL}$ were spiked with cobalt ions to obtain final concentrations of $5 \times 10^{-7}, 8 \times 10^{-7}, 1 \times 10^{-6}, 3 \times 10^{-6}$ mol L $\mathrm{L}^{-1}$ in order to perform recovery measurements. One half of each sample was analysed with Co-SPISE and the other by adsorptive stripping voltammetry (AdsSV). The $1.0 \times 10^{-3} \mathrm{~mol} \mathrm{~L}^{-1} \mathrm{NaNO}_{3}$ solution was used as a background solution in potentiometric measurements.

\section{RESULTS AND DISCUSSION}

In this paper single-piece solid-contact cobalt-selective electrodes with a polymeric membrane containing various imidazolium-based ionic liquids with chloride anions were studied. The effect of the ionic liquid used on sensor performance was evaluated by comparing it to a sensor having a membrane based on conventional ionic additive KTpClPB without ionic liquid.

It may be seen in Table 1 that all of the studied electrodes exhibited sensitivity to $\mathrm{Co}^{2+}$ ions but their parameters were different for particular electrodes. It all depends on the membrane components used, both the plasticizer and ionic additive. The plasticizer is an important component of the ion-selective membrane which affects both the selectivity and measuring range of the ISEs. Among the three plasticizers used, the TBP+TEHP (mixture 1:1) turned out to be the best membrane solvent. The electrode with membranes based on this membrane solvent exhibited a lower detection limit and a wider measuring range in comparison with electrodes having membranes plasticized by NPOE or TBP.

The lipophilic ionic additive performs some important functions in the membrane. First of all, it inhibits the interfering effect of anions from the aqueous phase, which may undergo coextraction with the cation into the membrane in the form of ionic pairs. Secondly, it reduces membrane resistance, which favourably affects the time required to generate a stable electrode potential. The effect of ionic additives of various ionic liquids and KTpClPB on the potential response of the studied cobalt electrodes is shown in Fig. 2, where it can be seen that ionic liquids act more effectively as the ionic membrane component than
$\mathrm{KTpCIPB}$. The best response was exhibited by ISE 13, it is based on EMImCl and a plasticizer TBP+TEHP (mixture $1: 1)$ : therefore this electrode was selected for further studies.

In our previous papers, we demonstrated that the properties of solid-contact electrodes, such as the detection limit and selectivity also depend on the procedure used for electrode conditioning (Wardak, 2012b; Wardak, 2014, 2015). Therefore the next step of the study was the optimization of cobalt concentration in the conditioning solution. The calibration curves of ISE-13 obtained for four conditioning procedures are presented in Fig. 3. As expected, lowering the cobalt concentration in the conditioning solution down

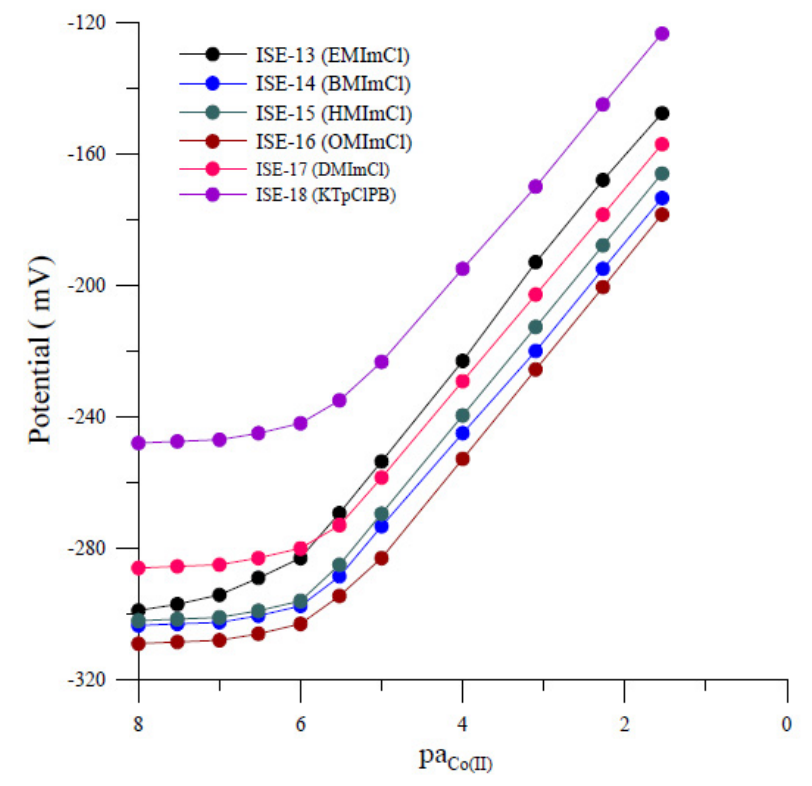

Fig. 2. Effect of ionic additive to the membrane phase on cobalt electrode response.

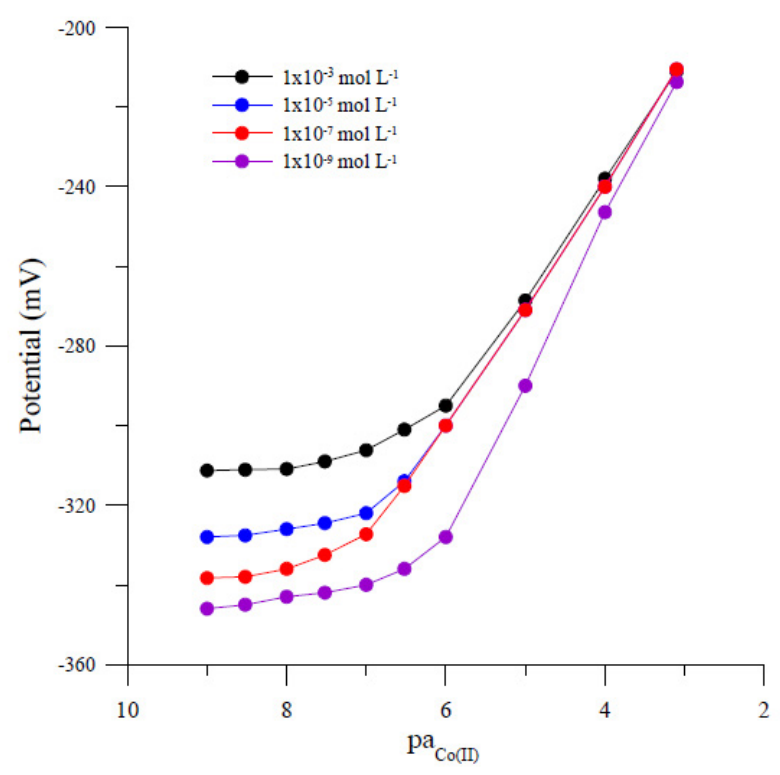

Fig. 3. Effect of cobalt concentration in conditioning solution on the response of ISE-13. 
to $1 \times 10^{-7} \mathrm{~mol} \mathrm{~L}^{-1}$ led to an improvement in the detection limit. The detection limit of ISE-13 was improved from $2.9 \times 10^{-7}$ to $5.6 \times 10^{-8} \mathrm{~mol} \mathrm{~L}^{-1}$, as a result of the optimization of the conditioning solution. This effect may be explained by the limitation of ion leaching from the membrane to the sample solution after conditioning in more diluted solutions. Further decreasing the cobalt content in the conditioning solution did not have the expected effect on electrode response which was super-Nernstian at low concentrations after soaking the electrode in a $1 \times 10^{-9} \mathrm{~mol} \mathrm{~L}^{-1}$ solution.

The most important parameter of any ion-selective electrode is its response to the primary ion in the presence of interfering ions. This factor is expressed by potentiometric selectivity coefficients. A comparison of the selectivity coefficients obtained for ISE 18 based on KTpClPB and ISE 13 based on EMImCl are presented in Fig. 4. Both electrodes had the same membrane components except for the ionic additive. The introduction of EMImCl to the membrane phase caused a notable improvement in electrode selectivity. Similar results were observed in the case of other electrodes based on ionic liquids. Better values of selectivity coefficients obtained for the electrodes based on ionic liquids as compared with those of the electrodes based on KTpClPB are due to differences in ion-exchanging properties. Ionic liquids present in the membrane have very weak ion-exchanging properties (Wardak 2012a; Wardak and Lenik, 2013) and because of that they do not increase the possibility of the extraction of interfering ions, however, they increase ionic strength in the membrane and thereby facilitate primary ion extraction. The level of ionic liquid in the membrane may largely exceed the ionophore concentration, which, however, does not cause any loss of selectivity. On the other hand, a lipophilic salt such as $\mathrm{KTpClPB}$, possessing ion-exchanging properties, increases the extraction of all cations and thus reduces electrode selectivity (Wardak and Lenik, 2013). Certainly, this effect depends on the concentration of the lipophilic salt in the membrane, which must be carefully selected. Too much salt added as an ionic exchanger can cause a loss of selectivity toward the primary ion (Armstrong and Horvai, 1990). This effect has not been observed in the case of ionic liquid.

The response time of the electrodes being studied depends on the cobalt concentration in the sample solution and it is longer in diluted solutions. In all cases the response time of the electrodes based on ionic liquid was shorter than the response time of the electrodes based on $\mathrm{KTpCIPB}$. For ISE -13 the maximum value of the response time in $1 \times 10^{-7} \mathrm{~mol} \mathrm{~L}^{-1}$ was $10 \mathrm{~s}$ but in more concentrated solutions up to $1 \times 10^{-5} \mathrm{~mol} \mathrm{~L}^{-1}$ it was shorter by $5 \mathrm{~s}$. For ISE18 the response time was about two times longer, 20-25 s in $1 \times 10^{-6}-1 \times 10^{-5} \mathrm{~mol} \mathrm{~L}^{-1}$ solutions and $10 \mathrm{~s}$ in the range of $1 \times 10^{-4}-1 \times 10^{-1} \mathrm{~mol} \mathrm{~L}^{-1}$.

The reversibility, stability and reproducibility of the electrode response are important parameters from the analytical application point of view. The green curve in Fig. 5

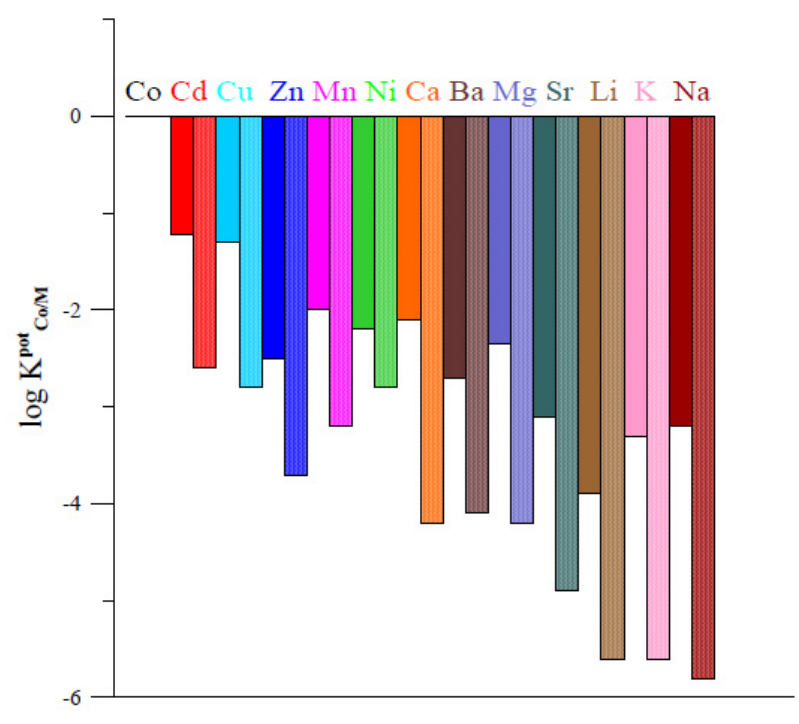

Fig. 4. Comparison of selectivity coefficients values for the studied sensors: ISE-18 based on KTpCIPB (1st column) and ISE-13 based on $\mathrm{BMImCl}$ (2nd column).

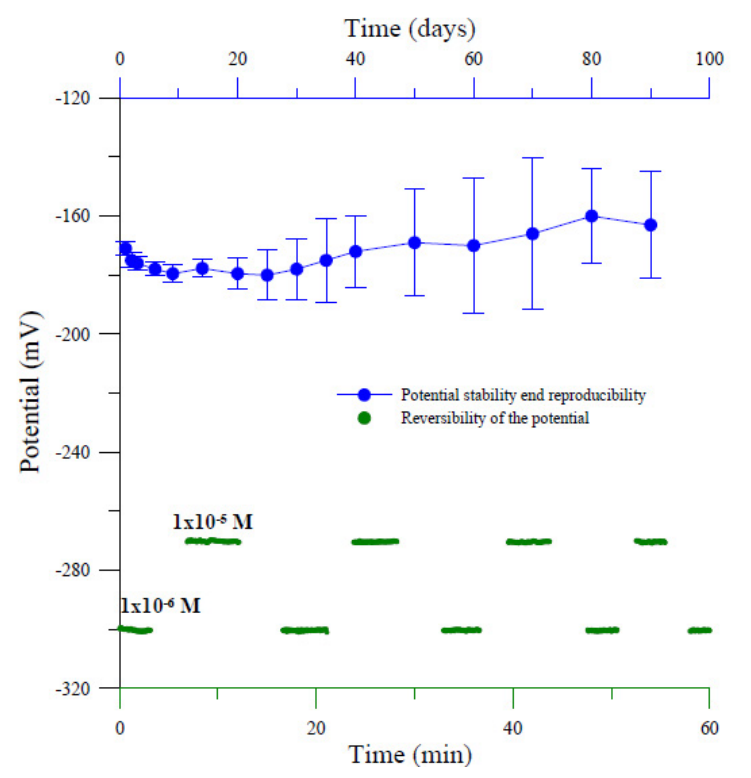

Fig. 5. Reversibility of the response of ISE-13 based on EMImCl (curve green) and changes in electrode potential with time determined in $0.1 \mathrm{~mol} \mathrm{~L}^{-1} \mathrm{Co}\left(\mathrm{NO}_{3}\right)_{2}$ (curve blue). The standard deviations given on the plot are determined for the same three electrodes.

shows the potential of ISE-13 recorded alternately in solutions at two different concentrations. The mean potential values obtained from four measurements were $-300.23 \pm$ 0.19 and $-269.39 \pm 0.13 \mathrm{mV}$ in solutions of $1 \times 10^{-6} \mathrm{M}$ and $1 \times 10^{-5} \mathrm{M}$, respectively. These results are evidence of the full reversibility of the tested sensor. The long-term stability and reproducibility of the electrode potential were also studied. The results obtained for ISE-13 are presented 


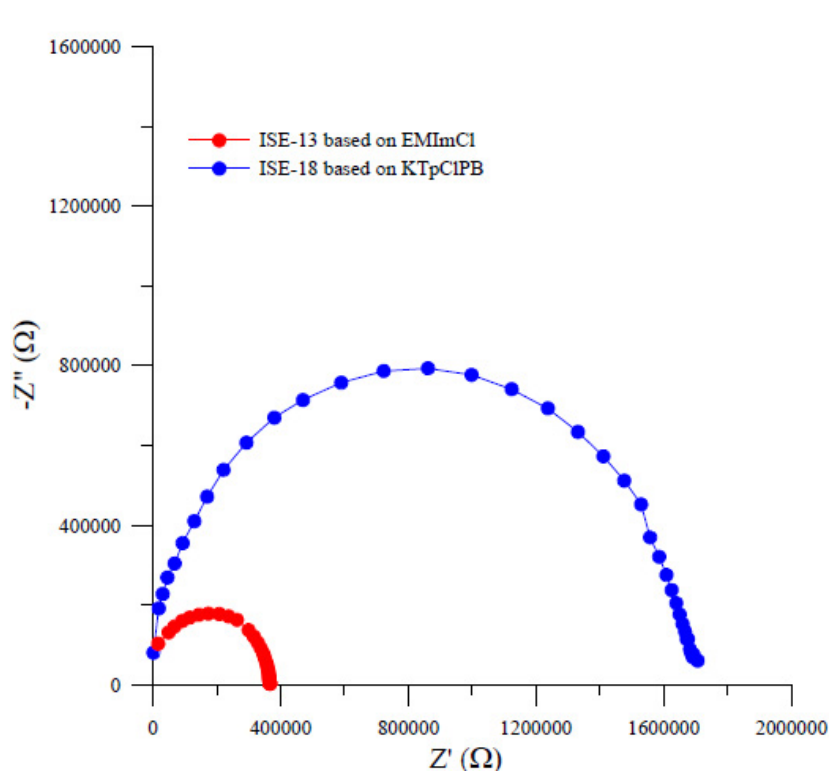

Fig. 6. Impedance spectra of ISE-13 (red) and ISE-18 (blue) recorded in $0.01 \mathrm{~mol} \mathrm{~L}^{-1} \mathrm{Co}\left(\mathrm{NO}_{3}\right)_{2}$. The spectra were recorded at the open circuit potential in the frequency range $100 \mathrm{~Hz}-1000 \mathrm{kHz}$.

in Fig. 5 (blue curve) where it may be observed that the proposed electrode exhibited a stable and reproducible potential. The potential drift calculated from $\Delta \mathrm{E} / \Delta \mathrm{t}$ was $1.23 \mathrm{mV}$ day $^{-1}$ durin $\mathrm{g}$ the first three days and $0.15 \mathrm{mV}$ day $^{-1}$ over the remainder of the study (3-90 days).

Electrochemical impedance spectroscopy is a very sensitive technique that allows for the study of electrode processes. Regarding ion-selective electrodes, this technique makes it possible to determine membrane resistance and charge transfer processes at the membrane/internal electrode interface.

Exemplary impedance spectra of ISE-13 based on EMImCl and ISE-18 based on KTpCIPB are shown in Fig. 6. They are in the form semicircles related to the bulk resistance $R_{b}$ of the ion-selective membrane and its geometric capacitance (Radu et al., 2010). It may be seen in Figure 6 that the bulk resistance decreased from $1680 \mathrm{k} \Omega$ (ISE-18) to $383 \mathrm{k} \Omega$ (ISE-13). This was obviously due to the presence of ionic liquid in the membrane phase. The obtained results showed that IL more effectively decreases membrane resistance than phenylborate derivatives.

In order to demonstrate the practical usefulness of the proposed Co-ISE, the cobalt concentrations in real water samples including river, lake and ground water were detected by direct potentiometry. The water samples were collected from a river, a lake and a well located near a biogas plant. The addition of cobalt and other trace elements to bioreactors is used to create optimal conditions for the microorganisms present in the digester and improve the capacity of the biogas plant. However, supplementation with trace metals could lead to an increase in the release of these metals into the environment. The analysis was performed using the standard addition technique. Adsorptive stripping voltammetry was the control method used for the determination of cobalt in the water samples. The results are summarized in Table 2. It may be seen that the results obtained using the potentiometric method are comparable with those obtained by AdSV analysis. Thus, the proposed single-piece Co-selective electrode provides a good alternative for the determination of $\mathrm{Co}^{2+}$ in real samples.

Table 2. Determination of cobalt in river water, lake water and groundwater samples (unspiked and spiked) by direct potentiometry and comparison with analyses by adsorptive striping voltammetry

\begin{tabular}{|c|c|c|c|}
\hline Sample & $\begin{array}{c}\text { Cobalt detected by } \\
\text { Co-SPISE }^{\mathrm{a}}\left(\mu \mathrm{g} \mathrm{L}^{-1}\right)(\mathrm{n}=4)\end{array}$ & Recovery (\%) & $\begin{array}{l}\text { Cobalt detected by AdSV } \\
\left(\mu \mathrm{g} \mathrm{L}^{-1}\right)(\mathrm{n}=3)\end{array}$ \\
\hline River water & $17.8 \pm 0.8$ & - & $18.4 \pm 1.3$ \\
\hline River water $+29.5\left(\mu \mathrm{g} \mathrm{L}^{-1}\right) \mathrm{Co}^{2+}$ & $46.3 \pm 2.2$ & 98.0 & $47.3 \pm 3.0$ \\
\hline River water $+47.2\left(\mu \mathrm{g} \mathrm{L}^{-1}\right) \mathrm{Co}^{2+}$ & $65.8 \pm 2.5$ & 101.3 & $64.2 \pm 4.2$ \\
\hline River water $+59.0\left(\mu \mathrm{g} \mathrm{L}^{-1}\right) \mathrm{Co}^{2+}$ & $77.8 \pm 3.0$ & 101.3 & $79.3 \pm 5.4$ \\
\hline River water $+177.0\left(\mu \mathrm{g} \mathrm{L}^{-1}\right) \mathrm{Co}^{2+}$ & $193.0 \pm 6.0$ & 98.8 & $199.0 \pm 11.0$ \\
\hline Lake water & $27.1 \pm 1.2$ & - & $29.1 \pm 2.0$ \\
\hline Lake water $+29.5\left(\mu \mathrm{g} \mathrm{L}^{-1}\right) \mathrm{Co}^{2+}$ & $57.8 \pm 2.0$ & 102.1 & $59.5 \pm 3.5$ \\
\hline Lake water $+47.2\left(\mu \mathrm{g} \mathrm{L}^{-1}\right) \mathrm{Co}^{2+}$ & $74.2 \pm 3.4$ & 99.9 & $72.6 \pm 5.6$ \\
\hline Lake water $+59.0\left(\mu \mathrm{g} \mathrm{L}^{-1}\right) \mathrm{Co}^{2+}$ & $86.8 \pm 4.5$ & 100.8 & $86.4 \pm 5.4$ \\
\hline Lake water $+177.0\left(\mu \mathrm{g} \mathrm{L}^{-1}\right) \mathrm{Co}^{2+}$ & $204.0 \pm 7.0$ & 99.7 & $210.0 \pm 11.0$ \\
\hline Groundwater & $34.5 \pm 3.5$ & - & $36.2 \pm 5.4$ \\
\hline Groundwater $+29.5\left(\mu \mathrm{g} \mathrm{L}^{-1}\right) \mathrm{Co}^{2+}$ & $64.7 \pm 3.9$ & 101.2 & $68.1 \pm 5.0$ \\
\hline Ground water $+47.2\left(\mu \mathrm{g} \mathrm{L}^{-1}\right) \mathrm{Co}^{2+}$ & $79.1 \pm 5.2$ & 96.9 & $79.2 \pm 9.1$ \\
\hline Groundwater $+59.0\left(\mu \mathrm{gL}^{-1}\right) \mathrm{Co}^{2+}$ & $96.3 \pm 6.4$ & 102.9 & $98.7 \pm 10.0$ \\
\hline Groundwater $+177.0\left(\mu \mathrm{g} \mathrm{L}^{-1}\right)$ & $221.0 \pm 10.0$ & 104.6 & $218.0 \pm 12.0$ \\
\hline $\mathrm{Co}^{2+}$ & & & \\
\hline
\end{tabular}

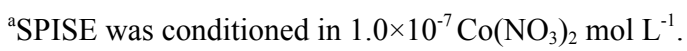




\section{CONCLUSIONS}

1. Modification of membrane composition by ionic liquid allows one to obtain single-piece Co-sensitive ionselective electrodes in a simple and fast way.

2. Among the studied imidazolium-based ionic liquids, the most suitable for the preparation of cobalt sensitive membranes is 1-ethyl-3-methyl imidazolium chloride.

3 . The presence of ionic liquid in the polymeric membrane phase results in a decrease in membrane resistance and has a valuable effect on sensor performance i.e. lowering the detection limit, shortening response time, enhancing selectivity and improving long-term stability.

4. The electrode response depends on the cobalt content in the conditioning solution. The optimal cobalt concentration in the conditioning solution was found to be $1.0 \times 10^{-7} \mathrm{~mol} \mathrm{~L}^{-1}$.

5. The proposed SPISE is a simple and economic analytical device for monitoring cobalt content in surface and ground water samples.

Conflict of interest: The Authors do not declare conflict of interest.

\section{REFERENCES}

Arinola O.G., Nwozo S.O., Ajiboye J.A., and Oniye A.H., 2008. Evaluation of trace elements and total antioxidant status in Nigerian cassava processors. J. Nutr., 7, 770-772. https://doi.org/10.3923/pjn.2008.770.772

Armstrong R.D. and Horvai G., 1990. Properties of PVC based membranes used in ion-selective electrodes. Electrochim. Acta, 35, 1-7. https://doi.org/10.1016/0013-4686(90)85028-1

Bakker E., Pretsch E., and Bühlman P., 2000. Selectivity of potentiometric ion sensors. Anal. Chem., 72, 1127-1133. https://doi.org/10.1021/ac991146n

Barceloux D.G. and Barceloux D., 1999. Cobalt. Clin. Toxicol., 37, 201-216.

Bobacka J., Ivaska A., and Lewenstam A., 2008. Potentiometric ion sensors. Chem. Rev., 108, 329-351. https://doi.org/10.1021/cr068100w

Buck R.P. and Lindner E., 1994. Recommendations for nomenclature of ion-selective electrodes Pure Appl. Chem., 66, 2527-2536. https://doi.org/10.1351/pac199466122527

Cadogan A., Gao Z., Lewenstam A. and Ivaska A., 1992. Allsolid-state sodium-selective electrode based on a calixarene ionophore in a poly(vinyl chloride) membrane with a polypyrrole solid contact. Anal. Chem., 64, 2496-2501. https://doi.org/10.1021/ac00045a007

Fibbioli M., Morf W.E., Badertscher M., De Rooij N.F., and Pretsch E., 2000. Potential drifts of solid-contacted ionselective electrodes due to zero-current ion fluxes through the sensor membrane. Electroanalysis, 12, 1286-1292. https://doi.org/10.1002/1521-4109(200011)12: 16\%3C1286::AID-ELAN1286\%3E3.0.CO;2-Q

Fisher T. and Rystedt I., 1985. Hand eczema among hard-metal workers. Am. J. Ind. Med., 8, 381-394. https://doi.org/10.1002/ajim.4700080419
Guziński M., Lisak G., Sokalski T., Bobacka J., Ivaska A., Bocheńska M., and Lewenstam A., 2013. Solid contact Ion-selective electrodes with highly selective thioamide derivatives of p-tetr-butylcalix[4] arene for the determination of lead(II) in environmental samples. Anal. Chem., 85, 1555-1561. https://doi.org/10.1021/ac302772v

Hauser P.C., Chiang D.W.L. and Wright G.A., 1995. A potassiumion selective electrode with valinomycin based poly(vinyl chloride) membrane and a poly(vinyl ferrocene) solid contact. Anal. Chim. Acta, 302, 241-248. https://doi.org/10.1016/0003-2670(94)00472-x

Kida K., Shigematsu T., Kijima J., Numaguchi M., Mochinaga Y., Abe N., and Morimura S., 2001. Influence of $\mathrm{Ni}^{2+}$ and $\mathrm{Co}^{2+}$ on methanogenic activity and the amounts of coenzymes involved in methanogenesis. J. Biosci. Bioeng., 91, 590-595. https://doi.org/10.1263/jbb.91.590

Kim J. H., Gibb H. J., and Howe P.D., 2006. Cobalt and inorganic cobalt compounds, p.4, WHO Press, Geneva, Switzerland.

Lenik J. and Lyszczek R., 2016. Functionalized $\beta$-cyclodextrin based potentiometric sensor for naproxen determination. Mat. Sci. Eng. C-Mater., 61, 149-157. https://doi.org/10.1016/j.msec.2015.12.011

Lindfors T., 2009. Light sensitivity and potential stability of electrically conducting polymers commonly used in solid contact ion-selective electrodes. J. Solid State Electrochem., 13, 77-89. https://doi.org/10.1007/s10008-008-0561-Z

Lindfors T., Sundfors F., Höfler L., and Gyurcsányi R.E., 2009. FTIR-ATR study of water uptake and diffusion through ion-selective membranes based on plasticized poly(vinyl chloride). Electroanalysis, 21, 1914-1922.

https://doi.org/10.1002/elan.200904609

Lindner E. and Umezawa Y., 2008. Performance evaluation criteria for preparation and measurement of macro- and microfabricated ion-selective electrodes (IUPAC Technical Report). Pure. Appl. Chem., 80, 85-104. https://doi.org/10.1351/pac200880010085

Maj-Zurawska M. and Lewenstam A., 2011. Selectivity coefficients of ion-selective magnesium electrodes used for simultaneous determination of magnesium and calcium ions. Talanta, 87, 295-301. https://doi.org/10.1016/j.talanta.2011.09.023

Michalska A., Wojciechowski M., Jędral W., Bulska E., and Maksymiuk K., 2009. Silver and lead all-plastic sensorspolyaniline vs. poly(3,4- ethyledioxythiophene) solid contact. J. Solid State Electrochem., 13, 99-106. https://doi.org/10.1007/s10008-008-0563-X

Moulin J.J., Wild P., Mur J.M., Fournier-Betz M., and MercierGollay M., 1993. A mortality study of cobalt production workers: An extension of the follow-up. Am. J. Ind. Med., 23, 281-288. https://doi.org/10.1002/ajim.4700230205

Paczosa-Bator B., Migdalski J., and Lewenstam A., 2006. Conducting polymer films as model biological membranes: Electrochemical and ion-exchange properties of poly(pyrrole) films doped with asparagine and glutamine. Electrochim. Acta, 51, 2173-2181. https://doi.org/10.1016/j.electacta.2005.03.084

Pais I., and Jones Jr. J.B., 1997. The Handbook of Trace Elements, St. Lucie Press, Florida, USA. 
Pięk M., Piech R., and Paczosa-Bator B., 2015. Improved nitrate sensing using solid contact ion selective electrodes based on TTF and its radical salt. J. Electrochem. Soc., 162, B257- B263. https://doi.org/10.1149/2.0631510jes

Radu A., Antrasova-Ivanowa S., Paczosa-Bator B., Danielewski M., Bobacka J., Lewenstam A., and Diamond D., 2010. Diagnostic of functionality of polymer membrane - Based ion selective electrodes by impedance spectroscopy. Anal. Methods, 2, 1490-1498. https://doi.org/10.1039/c0ay00249f

Sokalski T., Zwickl T., Bakker E., and Pretsch E., 1999. Lowering the detection limit of solvent polymeric ion-selective electrodes. 1. Modeling the Influence of Steady-State Ion Fluxes Anal. Chem., 71, 1204-1209. https://doi.org/10.1021/ac980944v

Wardak C., 2009. Ionic liquids as new lipophilic additives to the membrane of lead opn-selective electrodes with solid contact. Int. J. Environ. Anal. Chem., 89, 735-748. https://doi.org/10.1080/03067310902887642

Wardak C., 2012a. Ionic liquids improve analytical parameters of cadmium ion-selective electrodes with solid contact. Sensor Lett., 10, 1000-1006. https://doi.org/10.1166/sl.2012.2330
Wardak C., 2012b. A comparative study of cadmium ion-selective electrodes with solid and liquid inner contact. Electroanalysis, 24, 85-90. https://doi.org/10.1002/elan.201100362

Wardak C., 2014. Solid contact $\mathrm{Zn}^{2+}$ - selective electrode with low detection limit and stable and reversible potential. Centr. Eur. J. Chem., 12, 354-364. https://doi.org/10.2478/s11532-013-0390-5

Wardak C., 2015. Solid contact cadmium ion-selective electrode based on ionic liquid and carbon nanotubes. Sens. Actuators B: Chem., 209, 131-137. https://doi.org/10.1016/j.snb.2014.11.107

Wardak C. and Grabarczyk M., 2016. Analytical application of solid contact ion-selective electrodes for determination of copper and nitrate in various food products and drinking water. J. Environ. Sci. Heal. B, 51, 519-524. https://doi.org/10.1080/03601234.2016.1170545

Wardak C. and Lenik J., 2013. Application of ionic liquid to the construction of $\mathrm{Cu}(\mathrm{II})$ ion-selective electrode with solid contact. Sens. Actuators B: Chem., 189, 52-59. https://doi.org/10.1016/j.snb.2012.12.065 